\title{
Mucor racemosus IgE Measurement
}

National Cancer Institute

\section{Source}

National Cancer Institute. Mucor racemosus IgE Measurement. NCI Thesaurus. Code C130096.

A measurement of the Mucor racemosus IgE in a biological specimen. 